\title{
Women's attitudes towards children and motherhood: A predictor of future childlessness?
}

\author{
Melissa Graham \\ Deakin University \\ Carly Smith \\ Deakin University \\ Margaret Shield \\ Deakin University
}

\begin{abstract}
Pronatalism expects and presumes that all women will be mothers, and stereotypes, stigmatises and excludes those who fail to conform. Yet, within the context of pronatalism, little is known about women without children's attitudes towards motherhood, and their subsequent childbearing. This study aimed to determine if women's attitudes towards children and motherhood predicted future motherhood status, using data from the Negotiating the Life Course Study. Women 18 years and over at Wave 1, who did not have children, were included in the analysis $(n=122)$. Logistic regression was used to predict motherhood status at Wave 4 based on attitudes at Wave 1. A positive attitude toward the importance of children in one's life increased the likelihood of future motherhood, while believing children negatively impact on freedom increased the likelihood of not future childlessness. Findings also suggested that attitudes relating to the burden of children, or the impact of children on a woman's career, are similar for those who do and do not become mothers. Women's attitudes towards children and motherhood may be a poor predictor of future childlessness. This study counters some of the negative attitudinal stereotypes towards childless women in a pronatalist society.
\end{abstract}

Keywords: Australia, childlessness, motherhood, attitudes

While the decision to have or not to have children is a personal one dependent on a variety of factors, in both Australia and internationally, women's social identity remains strongly linked to the status of motherhood, with most cultures situating women as mothers, a factor central to their own identity formation and the way they are defined by others (McQuillan, Greil, Shreffler, Wonch-Hill, Gentzler \& Hathcoat, 2012; Morrell, 2000). Social-cultural norms give substance to the definition of appropriate behaviours and transitions throughout the life path, which are tied to age and status, and the importance of committing to particular role identities, such as motherhood, in shaping women's behaviours and experiences (McQuillan, et al., 2012). In pronatalist societies, such as Australia (Graham \& Rich, 2012a; Graham \& Rich, 2012b; Heard, 2006; Jackson \& Casey, 2009), women who remain childless fail to achieve this social-cultural construction of 'woman' and consequently experience negative stereotyping (Mueller \& Yoder, 1997, 1999), stigma (Culley \& Hudson, 2005; Park, 2002; Rich, Taket, Graham \& Shelley, 2011) and social exclusion (Graham, Hill, Shelley, \& Taket, 2013; Hinton, Kurinczuk, \& Ziebland, 2010; Letherby \& Williams, 1999). "Despite changed social circumstances, motherhood continues to be presented as an indispensable rite of passage to female fulfilment. If a woman fails to have children she is somehow incomplete" (Dux \& Simic, 2008, p. 83).

Corresponding author: Melissa Graham (melissa.graham@deakin.edu.au) 
Despite this, in recent times, fertility trends in Australia (and internationally) have seen a later commencement of childbearing, an increasing proportion of those who remain childless (Carmichael \& Whittaker, 2007), and declining fertility rates (Australian Bureau of Statistics, 2012c). Reflecting these changes is the proportion of women remaining childless in Australia, with 31\% of all Australian women in 2011 aged 15 years or more without children, an increase of 3\% since 2006 (Australian Bureau of Statistics, 2012a). For women of peak childbearing age (25 to 44 years) there was a $50 \%$ increase in the number of childless women between 1986 and 2006 and an additional 8\% childless by 2011, with 34\% of women childless (Australian Bureau of Statistics, 2007; 2012a). For women 45 years and over, 11\% were childless in 2011, an increase of 5\% since 2006 (Australian Bureau of Statistics, 2012a). In 2000, it was estimated that if the current rate of childlessness were to continue, $24 \%$ of women would remain childless at the end of their reproductive life. However, the projected rate was estimated to be higher in the Australian Capital Territory (33\%) and Victoria (31\%) (Australian Bureau of Statistics, 2000).

Substantial amounts of research have examined declining fertility rates and the increased prevalence of women without children. However, most of this research has focused on reasons for the declining fertility rates within the context of the second demographic transition (Carmichael \& McDonald, 2003; Hara, 2008; Pinneli \& Di Cesare, 2005; van de $\mathrm{Kaa}, 2002$ ), strategies to increase the fertility rate (see for example, Drago, Sawyer, Shreffler, Warren and Wooden, 2009), the role of declining marriage rates on fertility actualisation, delayed childbearing, and the impact of greater participation in both education and employment (Australian Bureau of Statistics, 2012b; Carmichael \& McDonald, 2003; Hagestad \& Call, 2007; Hara, 2008; Kneale \& Joshi, 2008; McDonald, 1998; Miranti, McNamara, Tanton \& Yap, 2009; Shaw, 2011). Little attention has been given to the role of women's attitudes towards children and mothering.

Ajzen's (1991) Theory of Planned Behaviour proposes an individual's attitude towards a behaviour, their perception about the behaviour and the social normative processes, along with their perceived behavioural control, shape an individual's intention, which then leads to actual behaviours. This theory is of particular relevance when examining whether or not attitudes towards children and motherhood can predict future childlessness, as it enables normative and subjective beliefs to be considered (e.g. societal cultural constructs of womanhood equalling motherhood) (Arendall, 2000; Rich, Taket, Graham \& Shelley, 2011). Based on the Theory of Planned Behaviour, Ajzen and Klobas (2013) suggest the intention to have a child (or not as the case may be) is determined by three factors: behavioural, normative and control beliefs. Behavioural beliefs are concerned with the perceived consequences of the individual's behaviour (in this case to have or not to have children) and the personal assessments of both the negative and positive consequences of this behaviour. Normative beliefs refer to the perceived expectations of an individual's behaviour by those in their social networks and an individual's own motivation to fulfil these perceived expectations. In this context, the decision to procreate may be influenced by the perceived consequences of not having children in a pronatalist society, including negatively stereotyping childless women as women with a dislike of children who are career focused and selfish (Doyle, Pooley \& Breen, 2012; Gillespie, 2000; Letherby, 2002; Maher \& Saugeres, 2007; Mollen, 2006; Park, 2002), and excluding them from social networks (Doyle, et al., 2012). While behavioural beliefs are concerned with consequences of individual behaviour and normative beliefs are related to perceived social expectations by the individual, control beliefs are "concerned with the perceived presence of factors that can influence a person's ability to have a child" (Ajzen \& Klobas, 2013, p. 206).

According to the Theory of Planned Behaviour, "behavioral beliefs form the basis for the formation of attitudes" (Ajzen \& Klobas, 2013, p. 209) and perceived social support affects individuals' behavioural intentions, which is an important concern when considering the stigmatised position of the voluntarily childless (Blackstone \& Stewart, 2012). Miller (1994) 
argues there are three main social-normative influences that contribute to childbearing: norms and values within society and its institutions (for example pronatalism); perceived attitudes and behaviours of people within a person's social network; and the influences of the person's partner. However, as Kohler and colleagues' (2006) research demonstrates, societies where the expectations and norms are for an adult woman to have children, individual differences in fertility motivation may not be apparent. In contrast to this, in socially permissive societies fertility motivation may be critical.

An important distinction needs to be made at this point regarding fertility intentions and attitudes toward children and motherhood. Fertility intentions relate to an idea that one plans to carry out or act upon, in this instance to have or to not have children. A persons' attitude relates to how one feels or thinks about an idea, person, object or situation. This 'attitude' might sit somewhere on a continuum from very positive to very negative. While it is well established that intentions to have (or not to have) a child are strong predictors of fertility behaviours and indeed the outcome (child or no child), see for example Schoen and colleagues (1999); Langdridge, Sheeran and Connolly (2005, p. 123) argue there is limited knowledge regarding the reasons underlying fertility intentions and thus, little is known about women's attitudes and behaviours that precede their fertility intentions. Therefore, the focus of this research is on women's attitudes towards children and motherhood, rather than their future fertility intentions.

Previous research has demonstrated a strong link between attitudes and childbearing behaviour. For example, Barber (2001) found positive attitudes toward childbearing led to earlier childbearing, particularly among married women, but there was little effect for the non-married, supporting the notion that "attitudes do not affect behavior when that behavior is not socially supported" (p. 123). This is of particular significance given pronatalist ideologies within countries such as Australia, which encourage and expect all women to aspire to motherhood and 'other' women who do not mother. The theoretical framework tested in Miller's (1994) research on childbearing intentions suggests "both positive and negative childbearing motivations were the primary determinants of childbearing desires, and childbearing desires were the primary determinants of childbearing intentions". Shoen and colleagues (1997) study of American's using data from the 1987-88 National Survey of Families and Households found attitudes towards childlessness significantly influenced fertility intentions for those who were currently childless suggesting that fertility intention is motivated by the attitude, "It's better for a person to have a child than to go through life childless" (p. 348).

There is a paucity of research on women's attitudes towards children and motherhood and the impact of this on childbearing in Australia. While a small amount of research on women's attitudes towards children and/or motherhood exists, mostly it has been conducted internationally or so long ago it is likely to be out-dated and would not accurately account for contemporary Australian women's attitudes towards children or motherhood (see for example Callan, 1986a, 1986b). The small body of work undertaken in contemporary Australia suggests that more traditional views of women are associated with increased desires for a greater number of children. However, Holton and colleagues (2009) found no difference between women with and without children in relation to traditional attitudes. While this study provides some useful insights into attitudes towards motherhood, it is based on cross-sectional data and thus does not allow for a prospective examination of attitudes and subsequent motherhood status. Previous analysis of the Australian Negotiating the Life Course Study has examined childless people's (both men and women) fertility expectations (i.e. those who indicated wanting to have children in the future and those who did not intend to have children in the future) and attitudes toward children and motherhood (Mitchell \& Gray, 2007). However, the focus of their study was on the fertility expectations of the childless rather than how these attitudes led to subsequent motherhood or childlessness. Therefore, in bridging this knowledge deficit, the current study aimed to explore Australian 
women's attitudes towards children and motherhood and if these attitudes predicted future childlessness.

\section{Methods}

\section{Participants}

This study utilised data from the Negotiating the Life Course (NLC) Study - a longitudinal study designed to explore the changing life courses and decision-making processes of Australian people as society moves towards higher levels of gender equity (Australian Demographic \& Social Research Institute, 2009). The NLC study was undertaken by the Australian Demographic and Social Research Institute, Australian National University and the School of Social Science, University of Queensland between 1997 and 2009, with five waves of data collected to date (1997, 2000, 2003, 2006 and 2009); however only the first four waves of data were available for use in the current study (Australian Demographic \& Social Research Institute, 2009). The NLC study used a national random telephone survey which utilised the electronic version of the white pages as its sampling frame. People aged 18 to 54 years were included with only one participant from each household randomly selected for participation. Each participant was interviewed by trained Australian Bureau of Statistics (ABS) data collection officials (McDonald, Evans, Baxter \& Gray, 2000). The sample obtained was comparable to the overall Australian population regarding marital status, family status, employment status and age, but included a higher percentage of women (56\%) than men (44\%) (Baxter, Hewitt \& Haynes, 2008).

Cases included in the analysis were all women aged between 18 and 45 years at Wave 1 (1997) who reported that they were currently not a mother (defined as no biological, fostered, adopted or step-children) and thus were classified as childless. Women who reported being currently pregnant $(n=15)$ at Wave 1 were excluded. The total sample size available at Wave 1 was 323 women who were aged 18 to 45 years, currently childless and not pregnant. By Wave 4, only 122 women who participated in Wave 1 remained in the study and form the basis for the current analysis.

\section{Measures}

Independent variables examined included demographic characteristics (age, partner status, highest level of educational attainment, employment status and hours worked in the previous week) and attitudes towards children and motherhood. Partnered status was measured using a four category response option (not in a relationship, in a relationship, not living together, living in a relationship but not legally married, and married and living with spouse). Highest level of educational attainment was computed based on two items: what was the highest level of schooling completed and attainment of a post-school qualification. Employment status was computed based on two items: 'last week, did you have a paid job of any kind' and 'did you actively look for work at any time in the past four weeks'. Data were then coded as employed, not employed and looking for work, and not employed and not looking for work.

Nine items were asked in relation to attitudes towards children and motherhood. Item one (the likelihood of having a child in the future) was measured using a six-point scale from 'very likely' to 'definitely not'. This scale was then recoded in 'likely', 'not sure' and 'not likely'. An additional item was asked in relation to number of future children desired. The remaining seven items were measured using a five-point scale from strongly agree to strongly disagree. These were subsequently recoded into agree and disagree. The dependent variable of interest was motherhood status at Wave 4 and defined as a mother of biological, fostered, adopted or step-children or childless. 


\section{Data Analysis}

Data were analysed using descriptive statistics in the first instance to explore the characteristics of the women. Chi square for proportions were used to examine associations between categorical variables and motherhood status. Mean differences for continuous variables were examined using independent sample t-Tests. Logistic regression models were constructed to determine whether attitudes of childless women towards children and motherhood at Wave 1 (1997) predicted childlessness at Wave 4 (2006).

\section{Results}

At Wave 1 there were 323 women aged 18 to 45 years who were currently childless and not pregnant with a mean age of 27.7 years $(S D=7.1)$. Nearly half of the women $(46.4 \%)$ were not in a relationship, a third (34.5\%) of the women had completed secondary school, $37 \%$ were currently studying, and the majority of women were employed $(84.5 \%)$ with the highest proportion identifying as 'intermediate clerical, sales and service workers' (25.4\%) or 'professionals' (25\%) (Table 1). The hours worked in the previous week ranged from zero to 91 hours with a mean of 40.82 hours $(S D=12.7)$. Of these, $75.9 \%$ of currently childless women indicated that it was likely that they would have children in the future. Of the 323 childless women who participated in Wave 1 , only 122 women participated in Wave 4, of which $41.8 \%(n=51)$ were mothers and $58.2 \%(n=71)$ were childless.

Table 1: Demographic characteristics of the childless women at Wave 1

\begin{tabular}{lll}
\hline & Number & Percent \\
\hline Partnered status (n= 323) & & 18.9 \\
Married and living with spouse & 61 & 46.4 \\
Not in a relationship & 150 & 20.4 \\
In a relationship, not living together & 66 & 14.2 \\
Living in a relationship but not legally married & 46 & 30.4 \\
\hline Highest education level achieved $(\mathbf{n}=\mathbf{3 1 6})$ & & 14.2 \\
Tertiary Education (post-secondary) & 46 & 34.5 \\
Secondary school not completed & 109 & 20.9 \\
Completed secondary school & 66 & \\
Post-secondary school & & 7.7 \\
\hline Employment status (n= 323) & 25 & 84.5 \\
Not employed and not looking for work & 273 & 7.7 \\
Employed & 25 & 3.7 \\
Not employed and looking for work & & 25.0 \\
\hline Occupation (n= 268) & 10 & 14.6 \\
Managers and administrators & 67 & 4.9 \\
Professionals & 39 & 8.2 \\
Associate professionals & 13 & 25.4 \\
Tradespersons and related workers & 22 & 14.2 \\
Advanced clerical and service workers & 68 & 4.1 \\
Intermediate clerical, sales and service workers & 38 & \\
Elementary clerical, sales and service workers & 11 & \\
Labourers and related workers & & \\
\hline
\end{tabular}

Table 2 shows the characteristics of the childless women at Wave 1 by motherhood status at Wave 4 . There is a statistically significant relationship between a woman's increasing age and motherhood status (OR $=1.09 ; 95 \% \mathrm{Cl} 1.03-1.15)$, suggesting that for every year older a woman gets, she is 1.09 times more likely to remain childless. Women who had only completed secondary school were more almost three times $(O R=2.84)$ more likely to remain childless $(95 \% \mathrm{Cl} 1.13$ - 7.13) than women who had completed tertiary (postsecondary) education, compared to mothers.

Table 3 presents women's attitudes towards children and motherhood at Wave 1 based on their Wave 4 motherhood status, along with logistic regression models of variables relating to the attitudes of women without children (at Wave 1) towards children and motherhood. 
When asked about the likelihood of having children in the future, women who indicated they were 'likely' to have children in the future were less likely to remain childless when compared to those who responded 'not sure' (OR $=0.08,95 \% \mathrm{Cl} 0.02-0.25)$. There was no statistically significant difference between mothers (mean $=2.39, \mathrm{SD}=0.91$ ) and women without children (mean $=2.19, \mathrm{SD}=0.78$ ) at Wave 4 based on the number of future children desired at Wave 1 (mean difference $=0.02, \mathrm{t}=0.19,95 \% \mathrm{Cl}-0.17-0.58$ ) and number of future children desired did not predict later childlessness (OR $=0.98,95 \% \mathrm{Cl} 0.44-1.27$ ).

Table 2: Logistic regression of the characteristics the women childless at Wave 1 as predictors of motherhood status at Wave 4

\begin{tabular}{lll}
\hline & $\mathrm{OR}^{\#}$ & $95 \% \mathrm{Cl}$ \\
\hline Age $(\mathrm{n}=122)$ & 1.09 & $1.03-1.15$ \\
\hline Partnered status (n= 122) & & - \\
Married and living with spouse & 2.50 & $0.97-6.44$ \\
Not in a relationship & 1.00 & $0.36-2.80$ \\
In a relationship, not living together & 1.43 & $0.40-5.16$ \\
Living in a relationship but not legally married & - & - \\
\hline Highest education level achieved (n = 120) & 2.64 & $0.79-8.74$ \\
Tertiary Education (post-secondary) & 2.84 & $1.13-7.13$ \\
Secondary school not completed & 1.87 & $0.67-5.21$ \\
Completed secondary school & & - \\
Post-secondary school & - & $0.59-2.97$ \\
\hline Currently studying (n = 120) & 1.33 & - \\
No & & $0.68-19.75$ \\
Yes & - & $0.58-42.80$ \\
\hline Employment status (n = 122) & 3.66 & $0.97-1.03$ \\
Not employed and not looking for work & 5.00 & 1.001 \\
Employed & & \\
Not employed and looking for work & & \\
\hline Hours worked in previous week (n = 93) & & \\
\hline The dependent variable is motherhood status defined as mother (biological, fostered, adopted or step-children) \\
or childless. The reference category is mother.
\end{tabular}

The regression analyses showed that, compared with women who disagreed, women who agreed with the statement 'a life without children is not fully complete' were more likely to have children $(\mathrm{OR}=0.36,95 \% \mathrm{Cl} 0.17-0.76)$, suggesting that women with the attitude that children make life complete predicted their becoming a mother later in life. Similarly, compared with women who disagreed that 'children have too great of an impact on the freedom of the mother', those who agreed were more likely not to have children (OR $=2.46$, $95 \% \mathrm{Cl} 1.11-5.44)$ suggesting that the attitude that children impede on the freedom and independence of the mother was a factor in remaining childless.

Of the women who agreed that 'it is better not to have children because they are such a burden', $83.3 \%$ did not have any future children, but the result was not statistically significant $(\mathrm{OR}=3.91,95 \% \mathrm{Cl} 0.44-34.51)$, suggesting there is no difference between women with and without children in relation to holding the attitude that children are burdensome. Similarly, of the women who agreed that 'watching children grow up is life's greatest joy', $45.5 \%$ became a mother, as did $34.5 \%$ of those who disagreed with the statement, however this attitude did not predict future motherhood (OR $=0.63,95 \% \mathrm{Cl} 0.26-1.51)$. Additionally, women who agreed with the statement 'whatever career a woman may have, her most important role in life is still that of becoming a mother', $42.7 \%$ became mothers as did $57.3 \%$ of those who disagreed, however holding this attitude did not predict future motherhood (OR $=0.84,95 \% \mathrm{Cl} 0.38-1.90)$. Finally, of the women who agreed 'a working mother can establish just as warm and secure a relationship with her children as a mother who does not work', $57.3 \%$ remained childless, as did $63.6 \%$ of those who disagreed $(\mathrm{OR}=0.77,95 \% \mathrm{Cl}$ $0.29-1.99$ ). 
Table 3: Logistic regression of childless women's attitude towards children and motherhood at Wave 1 as predictors of motherhood status at Wave 4

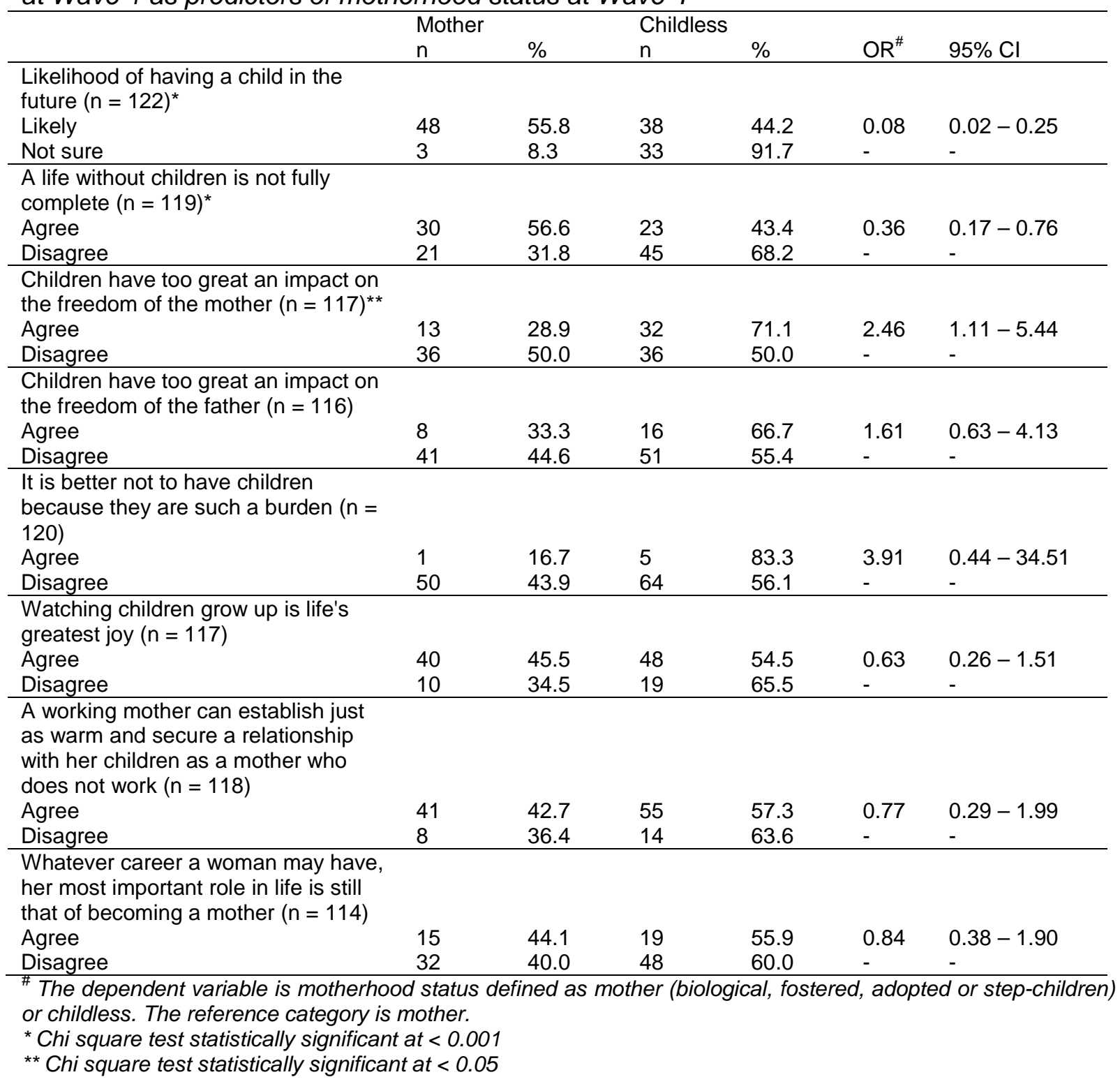

\section{Discussion}

This study aimed to describe Australian women's attitudes towards children and motherhood and explore if these attitudes predicted future childlessness. The Theory of Planned Behaviour postulates that attitudes towards a behaviour, subjective norms and perceived behavioural control form intentions that lead to behaviours (Ajzen, 1991). This theory is a useful tool when trying to conceptualise the relationship between women's attitudes towards children and motherhood and later childlessness status. Attitude toward the behaviour is concerned with the degree to which a person has a positive or negative assessment of the behaviour of interest (Ajzen, 1991). Arguably, a woman who has a negative attitude towards children and motherhood would be less likely to act on the behaviour to become a mother, and thus remain childless. Indeed, socially constructed stereotypes of childless women would lead us to expect that a woman's negative attitude towards children and motherhood would predict future childlessness. This study found that the belief 'a life without children is not fully complete' increases the likelihood of future motherhood, suggesting that positive attitudes towards children and motherhood do increase the likelihood of becoming a mother. Additionally, the belief that 'children have too great of an impact on the freedom of the mother' increased the likelihood of future childlessness, suggesting attitudes towards the 
impact of having children on one's life resulted in an increased likelihood of childlessness. Similarly, an American study using a national probability sample of 2,519 women found greater valuing of leisure time was associated with a decreased valuing of motherhood among women without children (McQuillan, Greil, Shreffler \& Tichenor, 2008). Further, a study examining personality traits and fertility among birth cohorts in the US found women's openness to experience (e.g. non-traditional values) is a personality trait associated with lower fertility (Jokela, 2012). Jokela (2012) posits social and cultural variations can change how people value parenthood comparatively to other lifestyle and "fertility decisions of individuals with different personality traits seem to be differentially sensitive to such changes in society" (p. 840).

However, the findings from this study also suggest that attitudes relating to the burden of children do not differ between women who went on to become mothers and those who remained childless. It is possible that these findings can be explained by 'subjective norms', that is the perceived social pressure to perform or not to perform the behaviour and the degree of perceived behavioural control (perceived ease or difficulty of performing the behaviour) (Ajzen, 1991). For example, it has been argued in countries with strong pronatalist ideologies, motherhood and the desire to have children is the norm, and as such it is expected women will become mothers (Callan, 1986a; Gillespie, 1999, 2000, 2003) driving exclusionary processes leading to stereotyping, stigmatisation and the exclusion of childless women (Carey, Graham \& Shelley, 2009; Culley \& Hudson, 2005; Doyle, et al., 2012; Rich, et al., 2011). Given such pervasive social and culture pressure upon women to be mothers, women's attitudes towards children and mothering may reflect little in their actual behaviours, but rather their behaviours are mediated by social pressures, norms and expectations. Ajzen (1991, p. 188) suggests "the relative importance of attitude, subjective norm, and perceived behavioural control in the prediction of intention is expected to vary across behaviors and situations". In the case of women's attitudes towards children and motherhood, it may be social pressures (at the societal, community and individual level) placed on women play a greater role in informing women's childbearing intentions and succeeding motherhood than their attitudes. An Australian study investigating women's fertility decision-making and women's perceptions of cultural representations of mothering ideals found that the decision-making process is often situational and associated with social expectations, and as such attitudes and decisions regarding fertility may change over time under the influence of differing social factors (Maher \& Saugeres, 2007). Ajzen and Klobas (2013) analysis of data from the Reproductive Decision Making in a Macro-Micro Perspective (REPRO) study, found the fertility intentions of childless women aged 24 to 34 years were strongly influenced by subjective norms and less so by beliefs. The findings also suggest attitudes relating to the impact of children on a woman's career do not differ between women who went on to become mothers and those who remained without children. This corroborates previous research which "debunks the myth that work-oriented women must be 'anti-child' or that motherhood-oriented women must be 'anti-work'" (McQuillan, et al., 2008, p. 492).

While this study has provided a prospective examination of, and insight into, women's attitudes towards children and motherhood as a possible predictor of childlessness based on a random sample of Australian women, it is not without limitations. The main limitation of this study included high numbers of losses to follow up. At Wave 1, there were 323 women who were aged between 18 and less than 45 years and identified as childless. Of these women, only 122 participated in Wave $4(37.8 \%)$. Thus the total sample size available for analysis was 122 women. This has implications for the statistical power of the study to examine differences between the two groups of women (those with and without children) at Wave 4. Analysis based on Wave 1 data suggests women who completed both Waves 1 and 4 were older at Wave 1 (mean age $=29.63$, SD $=7.30$ ) compared to women who were lost to follow-up by Wave 4 (mean age $=26.51, \mathrm{SD}=6.71$; mean difference $=-3.12, \mathrm{t}=-3.89, \mathrm{p}<$ 0.001). Further, there was a higher proportion of women who were not in a relationship 
(66.7\%), in a relationship but not living together (56.1\%), and living with their partner but not legally married (69.6\%) for those women who were lost to follow-up, when compared to women who remained in the study. However, these differences were not statistically significant different $\left(x^{2}=5.86\right.$, df $\left.=3, p=0.12\right)$. Similarly, there was no statistically significant difference between those lost to follow-up and those women who remained in the study in terms of highest level of education completed $\left(x^{2}=3.65\right.$, df $\left.=3, p=0.30\right)$, employment status $\left(x^{2}=1.18, d f=2, p=0.55\right.$ ) or hours worked in the previous week (mean difference = $0.89,-t=0.52, p=0.14)$. There was also no statistically significant difference in regards to likelihood of having children in the future $\left(x^{2}=3.59, \mathrm{df}=2, \mathrm{p}=0.17\right)$ or the desired number of children (mean difference $=0.01, t=0.11, p=0.65$ ).

Another limitation was the inability to gauge the complexity of women's attitudes towards children and motherhood using a quantitative approach. While the descriptive capacity of quantitative methods is no doubt useful in initial enquiries into this topic, future qualitative or mixed method approaches would be extremely effective in providing a more detailed account of the attitudes (and the reasons behind such attitudes) of contemporary Australian women towards children and motherhood. Further, as a result of the small sample size it was not possible to control for potentially confounding variables or changes in attitudes over time. Finally, women who are involuntarily childless (i.e. the infertile) were not able to be identified in this study and these women may indeed have a different attitude towards motherhood and children than the voluntarily childless.

\section{Conclusion}

The findings of this study add to the growing evidence which helps to understand the increasing trend of childlessness in Australia. It gives an exploratory insight into the possible link between a woman's attitude towards children and motherhood and their subsequent childlessness status later in life. Importantly, the findings from this study extend on previous research (see for example, McQuillan, Greil, Shreffler, \& Bedrous, 2015), moving beyond the importance of motherhood in women's live to also consider the role of attitudes towards children and motherhood in predicting fertility intentions and outcomes.

Results suggest while some attitudes may predict childlessness, on the whole the attitudinal differences between those with and without children were not significantly different. These findings are important as they counter the negative stereotypes of childless women as career-orientated with a dislike of children, adding further support to previous research with women without children that also suggests women without children do not consider themselves as career-orientated or 'career women' or that their career is the reason for their childlessness (Cannold, 2005; Dever \& Saugeres, 2004; Graham, et al., 2013; Maher \& Dever, 2004; Wheeler, 2005). These findings do not support social ideologies surrounding the centrality of children in women's lives, and thus are important in breaking down socially constructed stereotypes of childless women which have led to the stigmatisation and exclusion of women who do not mother. The implications of these findings pave the way for future studies in this area in seeking to understand the rising concentration of women remaining childless, and in breaking down some of the established stereotypes which seek to unjustly characterise childless women. This study suggests that there are variables other than women's attitudes towards children or motherhood influencing the increasing trend to remain childless. Further research is required in understanding the types of factors and the extent of their influence on motherhood and childlessness in a pronatalist society where to not mother excludes and 'others'.

\section{Acknowledgements}

We would like to acknowledge both the Negotiating the Life Course project and the Australian Social Science Data Archive for providing access to this data. Further we declare that those who carried out the original analysis and collection of the data bear no 
responsibility for the analysis or interpretation of the data as reported here. We would also like to thank the School of Health and Social Development who provided a funding for this work through the Research Small Grants Scheme. 


\section{References}

Ajzen, I. (1991). The theory of planned behavior. Organizational Behavior and Human Decision Processes, 50, 179-811.

Ajzen, I., \& Klobas, J. (2013). Fertility intentions: An approach based on the theory of planned behavior. Demographic Research, 29, 203-232.

Arendall, T. (2000). Conceiving and investigating motherhood: the decade's scholarship. Journal of Marriage and the Family, 62, 1192-1207.

Australian Bureau of Statistics. (2000). Births 2000. Canberra: Australian Bureau of Statistics.

Australian Bureau of Statistics. (2007). 1986, 1996 and 2006 Census of Population and Housing Customised Tables. Canberra: Australian Bureau of Statistics.

Australian Bureau of Statistics. (2012a). 2011 Census Community Profiles: Time Series Profile (Catalogue number 2003.0) Retrieved December 1, 2014 from http://www.censusdata.abs.gov.au/census_services/getproduct/census/2011/commu nityprofile/0?opendocument\&navpos $=220$

Australian Bureau of Statistics. (2012b). Australian Social Trends December 2012 Cat. No. 4102.0. Canberra: Australian Bureau of Statistics.

Australian Bureau of Statistics. (2012c). Births 2011. Canberra: Australian Bureau of Statistics.

Australian Demographic \& Social Research Institute. (2009). Negotiating the Life Course Retrieved November 23, 2012, from http://lifecourse.anu.edu.au/

Barber, J. S. (2001). Ideational influences on the transition to parenthood: Attitudes toward childbearing and competing alternatives. Social Psychology Quarterly, 64(2), 101127.

Baxter, J., Hewitt, B., \& Haynes, M. (2008). Life course transitions and housework: Marriage, parenthood, and time on housework. Journal of Marriage \& Family, 70(2), 259-272.

Blackstone, A., \& Stewart, M. D. (2012). Choosing to be childfree: Research on the decision not to parent. Sociology Compass, 6(8), 718-727.

Callan, V. J. (1986a). The impact of the first birth: Married and single wwomen prefering childlessness, one child, or two children. Journal of Marriage and the Family, 48(2), 261-269.

Callan, V. J. (1986b). Single women, voluntary childlessness and perceptions about life and marriage. Journal of Biosocial Science, 18(4), 479-487.

Cannold, L. (2005). What, no baby? Why women are losing the freedom to mother, and how they can get it back. Freemantle: Curtin University Books.

Carey, G., Graham, M., \& Shelley, J. (2009). Discourse, power and exclusion: The experiences of childless women. In A. Taket, B. Crisp, A. Nevill, G. Lamaro, M. Graham \& S. Barter-Godfrey (Eds.), Theorising social exclusion. London: Routledge.

Carmichael, G. A., \& McDonald, P. (2003). Fertility trends and differentials. In S-E. Khoo \& P. McDonald (Eds.), The Transformation of Australia's population 1970 - 2030. New South Wales: UNSW press.

Carmichael, G. A., \& Whittaker, A. (2007). Choice and circumstance: Qualitative insights into contemporary childlessness in Australia. European Journal of Population, 23, 111143.

Culley, L., \& Hudson, N. (2005). Diverse bodies and disrupted reproduction. International Journal of Diversity in Organisations, Communities \& Nations, 5(2), 117-125.

Dever, M., \& Saugeres, L. (2004). I forgot to have children! Untangling links between feminism, careers and voluntary childlessness. Journal of the Association for Research on Mothering, 6(2), 116-126.

Doyle, J., Pooley, J. A., \& Breen, L. (2012). A phenomenological exploration of the childfree choice in a sample of Australian women. Journal of Health Psychology, 18(3), 1-11.

Drago, R., Sawyer, K., Shreffler, K., Warren, D., \& M, Wooden. (2009). Did Australia's Baby Bonus Increase the Fertility Rate? Melbourne Institute Working Paper Series 
Working Paper No. 1/09. Melbourne: Melbourne Institute of Applied Economic and Social Research, The University of Melbourne.

Dux, M., \& Simic, Z. (2008). The Great Feminist Denial. Melbourne: Melbourne University Press.

Gillespie, R. (1999). Voluntary childlessness in the United Kingdom. Reproductive Health Matters, 7(13), 43-53.

Gillespie, R. (2000). When no means no: Disbelief, disregard and deviance as discourses of voluntary childlessness. Women's Studies International Forum, 23(2), 223-234.

Gillespie, R. (2003). Childfree and feminine: Understanding the gender identity of childless women. Gender and Society, 17(1), 122-136.

Graham, M., Hill, E., Shelley, J., \& Taket, A. (2013). Why are childless women childless? Findings from an exploratory study of childless women in Victoria, Australia. Journal of Social Inclusion, 4(1), 70-89.

Graham, M., \& Rich, S. (2012a). Representations of childless women in the Australian print media. Feminist Media Studies, 1-16.

Graham, M., \& Rich, S. (2012b). What's childless got to do with it? Alfred Deakin Research Institute, 2(36), 16.

Hagestad, G., \& Call, V. (2007). Pathways to Childlessness: A Life Course Perspective. Journal of Family Issues, 28(10), 1338-1361.

Hara, T. (2008). Increasing childlessness in Germany and Japan: Towards a childless society? International Journal of Japanese Sociology, 17, 42-62.

Heard, G. (2006). Pronatalism under Howard. People and Place, 14(3), 12-25.

Hinton, L., Kurinczuk, J. J., \& Ziebland, S. (2010). Infertility; isolation and the Internet: A qualitative interview study. Patient Education \& Counseling, 81, 436-441.

Holton, S., Fisher, J., \& Rowe, H. (2009). Attitudes toward women and motherhood: Their role in Austraian women's childbearing behaviour. Sex Roles, 91, 677-687.

Jackson, N., \& Casey, A. (2009). Procreate and cherish: A note on Australia's abrupt shift to pro-natalism. New Zealand Population Review, 35, 129-148.

Jokela, M. (2012). Birth-cohorts effects in the association between personality and fertility. Psychological Science, 23(8), 835-841.

Kneale, D., \& Joshi, H. (2008). Postponement and childlessness: Evidence from two British cohorts. Demographic Research, 19(58), 1935-1968.

Kohler, H.-P., Rodgers, J. L., Miller, W. B., Skytthe§, A., \& Christensen, K. (2006). Bio-social determinants of fertility. International journal of Andrology, 29, 46-53.

Langdridge, D., Sheeran, P., \& Connolly, K. (2005). Understanding the reasons for parenthood. Journal of Reproductive and Infant Psychology, 23(2), 121-133.

Letherby, G. (2002). Childless and bereft?: Stereotypes and realities in relation to 'voluntary' and 'involuntary' childlessness and womanhood. Sociological Inquiry, 72(1), 7-20.

Letherby, G., \& Williams, C. (1999). Non-motherhood: ambivalent autobiographies. Feminist Studies, 25(3), 719-728.

Maher, J. M., \& Dever, M. (2004). What matters to women: beyond reproductive stereotypes. People and Place, 12(3), 10-17.

Maher, J. M., \& Saugeres, L. (2007). To be or not to be a mother?: Women negotiating culutral representations of mothering. Journal of Sociology, 43(1), 5-20.

McDonald, P. (1998). Contemporary fertility patterns in Australia: First data from the 1996 Census. People and Place, 6(1), 1-13.

McDonald, P., Evans, A., Baxter, J., \& Gray, E. (2000). The Negotiating the Life Course Survey experience. Retrieved November 23, 2012, from http://lifecourse.anu.edu.au/publications/Discussion_papers/NLCDP001.pdf

McQuillan, J., Greil, A. L., Shreffler, K. M., \& Bedrous, A. V. (2015). The importance of motherhood and fertility intentions among U.S. women. Sociological Perspectives, 58(1), 20-35.

McQuillan, J., Greil, A. L., Shreffler, K. M., \& Tichenor, V. (2008). The importance of motherhood among women in the contemporary United States. Gender \& Society, 22(4), 477-496. 
McQuillan, J., Greil, A. L., Shreffler, K. M., Wonch-Hill, P. A., Gentzler, K. C., \& Hathcoat, J. D. (2012). Does the reason matter? Variations in childlessness concerns among U.S. women. Journal of Marriage and Family, 74(5), 1166-1181.

Miller, W. B. (1994). Childbearing motivations, desires, and intentions: A theoretical framework. Genetic, Social, and General Psychology Monographs, 120(2), 223-258.

Miranti, R., McNamara, J., Tanton, R., \& Yap, M. (2009). A narrowing gap? Trends in the childlessness of professional women in Australia 1986-2006. Journal of Population Research, 26(4), 359-379.

Mitchell, D., \& Gray, E. (2007). Declining fertility: intentions, attitudes and aspirations. Journal of Sociology, 43, 23-44.

Mollen, D. (2006). Voluntarily childfree women: Experiences and counseling considerations. Journal of Mental Health Counseling, 28(3), 269-282.

Morrell, C. (2000). Saying no: Women's experiences with reproductive refusal. Feminism \& Psychology, 10(3), 313-322.

Mueller, K., \& Yoder, J. (1997). Gendered norms for family size, employment, and occupation: Are there personal costs for violating them? Sex Roles, 36(3/4), 207-220.

Mueller, K., \& Yoder, J. (1999). Stigmatization of non-normative family size status. Sex Roles, 41(11/12), 901-919.

Park, K. (2002). Stigma management among the voluntary childless. Sociological Perspectives, 45(1), 21-45.

Pinneli, A., \& Di Cesare, M. (2005). Human fertility: sociodemographic aspects. Contraception, 72, 303-307.

Rich, S., Taket, A., Graham, M., \& Shelley, J. (2011). 'Unnatural', 'unwomanly', 'uncreditable' and 'undervalued': The significance of being a childless woman in Australian society. Gender Issues, 28(4), 226-247.

Schoen, R., Astone, N. M., Kim, Y. J., Nathanson, C. A., \& Fields, J. M. (1999). Do fertility intentions affect fertility behavior? Journal of Marriage and Family, 61(3), 790-799.

Schoen, R., Kim, Y. J., Nathanson, C. A., Jason, F., \& Astone, N. M. (1997). Why do Americans want children? Population and Development Review, 23(2), 333-358.

Shaw, R. L. (2011). Women's experiential journey towards voluntary childlessness: An interpretative phenomenological analysis. Journal of Community and Applied Social Psychology, 21, 151-163.

van de Kaa, D. J. (2002). The idea of a second demographic tranisition in industrialized countries. Paper presented at the Sixth Welfare Policy Seminar of the National Insitute of Population and Social Security, Tokyo, Japan.

Wheeler, J. (2005). Decision-making styles of women who choose not to have children. Paper presented at the 9th Australian Institute of Family Studies Conference, Melbourne. 


\section{Biographical notes}

Dr Melissa Graham is a Senior Lecturer and Deputy Director of the Centre for Health through Action on Social Exclusion (CHASE) in the School of Health and Social Development, Deakin University. Dr Graham has a particular interest in women's reproductive health including childlessness and social exclusion.

Ms Carly Smith was a Bachelor of Public Health and Health Promotion placement student in the Centre for Health through Action on Social Exclusion (CHASE) in the School of Health and Social Development, Deakin University.

Ms Margaret Shield was a Research Assistant in the Centre for Health through Action on Social Exclusion (CHASE) in the School of Health and Social Development, Deakin University. 